\title{
Pengendalian Kualitas Proses Pengemasan Gula Dengan Pendekatan Six Sigma
}

\author{
Aulia Kusumawati ${ }^{1}$, dan Lailatul Fitriyeni ${ }^{2}$ \\ Program Studi Teknik Industri, Fakultas Teknik, Universitas Serang Raya \\ aulia07@gmail.com, yeniunsera@gmail.com
}

\begin{abstract}
Abstrak -- Faktor utama untuk meraih kesuksesan bisnis dalam era globalisasi adalah kualitas. Pengendalian kualitas merupakan kunci dalam mempertahankan loyalitas konsumen. Dalam proses produksi perusahaan masih dijumpai produk yang dihasilkan tidak sesuai dengan spesifikasi yang telah ditentukan. Penelitian ini bertujuan untuk mengetahui nilai sigma dan faktor penyebab kerusakan pada proses produksi bagian bagging bagi perusahaan. Dengan melakukan pengendalian kualitas diharapkan dapat meraih tujuan perusahaan.Dalam penelitian ini, metode yang digunakan adalah Six Sigma dengan tahapan define, measure, analyze, improve. Hasil Six Sigma berupa pengukuran baseline kinerja perusahaan pada tahap pengukuran yaitu perusahaan pada kondisi 5,1 sigma dengan DPMO sebesar 162,4532. Faktor-faktor penyebab kecacatan pengemasan gula adalah kekurangtelitian dan ketrampilan operator, ketidakstabilan kecepatan conveyor, dan mesin jet, kondisi kebersihan mesin, kekurangakuratan mesin timbang, dan metode perawatan dan pengontrolan yang belum efektif.
\end{abstract}

Kata kunci: Kualitas; Proses Produksi; dan Six Sigma

\begin{abstract}
The main factor to achieve business success in the era of globalization is quality. Quality control is key in maintaining customer loyalty. In the company's production process is still found the resulting product does not comply with the specified specifications. This study aims to determine the value of sigma and factors causing damage to the production process of bagging section For companies with quality control is expected to achieve corporate goals. In this study, the methods used is Six Sigma with define, measure, analyze, improve. Six Sigma result is measurement of company performance baseline at measurement stage that is company at condition 5,1 sigma with DPMO equal to 162,4532. The factors causing the disability of sugar packing are lack of research and skill of the operator, instability of conveyor speeds and jet engine position, machine hygiene condition, lack of weighing machine, and ineffective treatment, and control method.
\end{abstract}

Keywords: Quality; Production Process; and Six Sigma

\section{PENDAHULUAN}

Kualitas merupakan standar karakteristik suatu produk (barang atau jasa) yang bertujuan untuk memuaskan kebutuhan pelanggan. Suatu kualitas yang baik dimana memiliki tujuan dan manfaat yang sejalan.Kualitas suatu produk (barang atau jasa) sangat penting sekali, karena itu merupakan kepuasan untuk konsumen dan juga produsen. Dengan memberikan kualitas yang terjamin kepada konsumen maka produsen akan mendapat kepercayaan dari konsumen dan memiliki hubungan bisnis yang baik pula. Konsumen dan produsen sama-sama mendapat keuntungan yang baik dari suatu kualitas produk atau jasa yang terjamin, terjaga, dan bermutu. Maka dari itu peranan suatu kualitas sangatlah penting untuk suatu produk atau jasa agar mampu berkompetisi secara efektif dengan pesaing serta dapat memahami mengenai kepuasan pelanggan lebih dalam dan juga memahami konsep untuk peningkatan kualitas produk atau jasa yang dihasilkan.

Dasar pemikiran pengendalian kualitas produk adalah menemukan cara terbaik dan unggul dalam persaingan dengan menghasilkan kualitas pada setiap tahap industri. Menurut Wisnubroto \& Rukmana (2015) kualitas setiap tahap industri bagi midlle management ke atas diperlukan alat dalam menyelesaikan masalah dengan total quality control melalui gugus kendali mutu yang berada pada unit masingmasing manajer industri.

Standar kualitas dari suatu produk tidak hanya ditentukan oleh $\mathrm{SNI}$, namun pelanggan ikut berperan menentukan kualitas produk yang diproduksi oleh perusahaan. dari hal tersebut, dapat disimpulkan bahwa pengendalian kualitas mempunyai tujuan mendapatkan kualitas output yang konsisten dengan spesifikasi produk yang diinginkan dan memenuhi syarat-syarat yang 
ditentukan oleh konsumen yang dapat meningkatkan kepercayaan dan kepuasan konsumen, membimbing mendapatkan keuntungan yang lebih besar melalui prosedur kerja yang baik, pengurangan produk cacat, penekanan biaya, dan peningkatan order yang baik.

Metode Six Sigma merupakan salah satu alat yang biasa digunakan dalam pengendalian kualitas produk. Metode ini mempunyai konsep menetapkan standar kualitas sampai mencapai 3,4 reject per satu juta kemungkinan. Dalam metode Six Sigma dibagi beberapa tahapan untuk mencapai peningkatan kualitas produk. Penggunaan metode Six Sigma dapat digunakan untuk mengetahui penyebab dan faktor-faktor yang mempengaruhi reject dengan tujuan untuk mengurangi produksi cacat (Salomon, Ahmad, \& Limanjaya, 2017). Dengan diketahui penyebab masalah cacat maka dapat dilakukan perbaikan untuk meminimalkan kemungkinan cacat yang terjadi.

Banyak penelitian yang membuktikan metode Six Sigma mampu meminimalkan cacat yang terjadi. Penelitian yang dilakukan Wibowo \& Aritonang (2014) memperoleh hasil penggunaan Six Sigma mampu meningkatkan menurunkan cacat produk sehingga level sigma meningkat 4,7 menjadi 5,0 dengan mendapatkan penghematan sebesar Rp. 4.877.443,40. Hal ini sesuai dengan yang dilakukan (Fransiscus, Juwono, \& Astari, 2014), (Wardhana, Harsono, \& Liansari, 2015) dan (Karenza, Adianto, \& Liansari, 2016) bahwa perbaikan kualitas produk mampu meningkatkan nilai sigma yang berdampak pada penurunan cacat produksi yang ada.

PT PDSU merupakan perusahaan yang bergerak di bidang industri makanan yang memproduksi sugar refinery dengan standar SNI, Halal, ISO 22000, dan FSSC 22000. Pada proses produksi selama penelitian masih dijumpai produk yang cacat, tidak sesuai dengan spesifikasinya. Reject yang terjadi ini apabila tidak ditangani secara berkelanjutan akan berdampak pada biaya produksi, produk yang terbuang, dan berkurangnya kepercayaan pelanggan.

Tujuan penelitian ini adalah untuk mengetahui nilai sigma yang didapatkan perusahaan saat ini. Selain itu untuk mengetahui faktor penyebab kerusakan pada proses produksi bagian bagging

\section{METODOLOGI PENELITIAN}

Penelitian ini menggunakan data kuantitatif yang diperoleh selama penelitian. Pengolahan data menggunakan tahapan six sigma (define, measure, analyze dan improve). Six Sigma merupakan metric yang diterjemahkan ke dalam proses pengukuran dengan menggunakan analisis statistik dan teknik untuk mengurangi cacat hingga 3,4 DPMO (Defect Per Million Opportunities) per satu juta kemungkinan cacat guna memuaskan pelanggan.

Menurut Salomon, Kosasih, \& Jap, (2017) Six sigma adalah pendekatan menyeluruh dalam menyelesaikan permasalahan dan meningkatkan proses melalaui DMAIC (Define, Measure, Analyse, Improve, Control). DMAIC merupakan jantung Six Sigma dalam menjamin voice of customer berjalan sesuai dengan kesemuanya proses sehingga menghasilkan produk yang memuaskan pelanggan.

\section{Define}

Define adalah langkah identifikasi permasalahan dalam proses yang sedang terjadi (Yanuarsih, Widaningrum, \& lqbal, 2012). Tahap ini merupakan langkah pertama dalam program peningkatan kualitas Six Sigma dengan cara melakukan identifikasi jumlah produk reject dan jenis - jenis reject yang terjadi. Setelah diketahui selanjutnya menentukan karakter kualitas atau disebut CTQ (Critical to Quality) yang digunakan untuk menggambarkan kebutuhan pelanggan mengenai produk gula maupun kemasan produknya.

\section{Measure}

Langkah kedua dalam pengaplikasian Six Sigma adalah measure atau pengukuran. Pada tahap kedua ini dilakukan pengukuran terhadap performansi sigma dengan tujuan untuk mengetahui tingkat kerja sekarang (baseline kinerja). Baseline kinerja sebagai satuan pengukuran dalam Defects PerMillon Opportunities (DPMO) atau tingkat kapabilitas sigma (Defrianto \& Farida, 2016). Tahapan perhitungan dimulai dari DPO, DPMO dan Nilai Sigma. Defect Per Opportunities (DPO) merupakan ukuran kegagalan yang dihitung dalam program peningkatan kualitas six sigma yang menunjukkan banyaknya cacat atau kegagalan persatu kesempatan.

$$
D P O=\frac{\text { banyak product cacat }}{\text { jumlah product yang diperiksa } x C T Q}
$$

Biasanya DPO ini apabila dikaitkan dengan konstanta 1.000 .000 akan menjadi DPMO (Defect Per Million Opportunities) dengan formula :

$$
D P M O=D P O \times 1.000 .000
$$


Nilai DPMO dikonversi menjadi nilai sigma dengan menggunakan microsoft excel dengan rumus perhitungan:

Konversi Nilai DPMO $=$ NORMSINV $((1.000 .000-$ DPMO)/1.000.000)+1.5.

\section{Analyze}

Pada tahap ini dilakukan analisis data berdasarkan pada akar permasalahan yang menyebabkan performansi sigma dalam proses menurun. Selain itu, mendaftar semua faktor yang berpengaruh (significant few opportunities) terhadap kualitas yang akan di improve, kemudian dipilih beberapa faktor yang dianggap paling berpengaruh.

\section{Improve}

Pada tahap ini dilakukan seleksi solusi dan tindakan yang diharapkan dapat meningkatkan performansi dari sigma. Langkah ini dapat dilakukan dengan memberikan rekomendasi perbaikan untuk meminimalkan kemungkinan cacat yang terjadi.

\section{PENGOLAHAN DATA DAN PEMBAHASAN}

Pengolahan data pada penelitian menggunakan tahapan Six Sigma dengan langkah-langkah sebagai berikut:

\section{Define}

Dalam setiap produksinya masih terdapat produk reject yang merupakan suatu kerugian. Hal ini akan diidentifikasi dengan melihat jumlah produk reject dari setiap kriteria reject, dan memaparkan karakteristik dari jenis cacat.

Tabel 4. Data Produksi dan Data Produk Reject Gula

\begin{tabular}{|c|c|c|c|c|c|c|c|}
\hline \multirow{2}{*}{ No. } & \multirow{2}{*}{ Bulan } & \multirow{2}{*}{ Satuan } & \multirow{2}{*}{ Baik } & \multicolumn{3}{|c|}{ Cacat } & \multirow{2}{*}{ Total } \\
\hline & & & & $\begin{array}{r}\text { Sobek } \\
\text { Karung }\end{array}$ & $\begin{array}{c}\text { Jahitan } \\
\text { lepas }\end{array}$ & $\begin{array}{l}\text { Gagal } \\
\text { Timbang }\end{array}$ & \\
\hline 1 & Oktober '15 & Karung & 796728 & 90 & 78 & 183 & 797079 \\
\hline 2 & November '15 & Karung & 693131 & 158 & 166 & 163 & 693618 \\
\hline 3 & Desember '15 & Karung & 581544 & 163 & 179 & 161 & 582047 \\
\hline 4 & Januari '16 & Karung & 239945 & 42 & 41 & 96 & 240124 \\
\hline 5 & Februari '16 & Karung & 669137 & 79 & 71 & 139 & 669426 \\
\hline 6 & Maret '16 & Karung & 715452 & 44 & 42 & 147 & 715685 \\
\hline 7 & April '16 & Karung & 740144 & 37 & 51 & 127 & 740359 \\
\hline 8 & Mei '16 & Karung & 611116 & 56 & 64 & 234 & 611470 \\
\hline 9 & Juni '16 & Karung & 754255 & 75 & 54 & 125 & 754509 \\
\hline 10 & Juli '16 & Karung & 807837 & 89 & 90 & 158 & 808174 \\
\hline 11 & Agustus '16 & Karung & 862359 & 54 & 69 & 158 & 862640 \\
\hline 12 & September '16 & Karung & 873531 & 86 & 77 & 178 & 873872 \\
\hline
\end{tabular}

Penentuan CTQ (Critical to Quality) digunakan untuk mengidentifikasi kebutuhan spesifik konsumen. CTQ dapat diartikan sebagai elemen dari proses yang berpengaruh langsung terhadap pencapaian kualitas yang diinginkan. Berdasarkan tabel 1 dapat diketahui karakteristik CTQ menjad 3 yaitu sobek karung ( kemasan karung sobek), jahitan lepas ( jahitan karung tidak merata) dan gagal timbang ( isi kapasitas produk tidak sesuai)

\section{Measure}

Setelah dilakukan pendefinisian masalah yang akan dianalisis selanjutnya pada tahap ini akan dihitung DPMO (Defect Per Million Opportunities) dan nilai Sigma untuk dapat mengetahui performansi kinerja perusahaan saat ini 
Contoh perhitungan : (pada bulan Oktober 2015)

$$
\begin{aligned}
& D P O=\frac{351}{797079 \times 3}=0,000146786 \\
& \begin{aligned}
D P M O & =0,000146786 \times 1000000 \\
& =146,786
\end{aligned}
\end{aligned}
$$

Nilai sigma $=$ NORMSINV $((1.000 .000$ $146,786) / 1.000 .000)+1.5$.

Nilai Sigma $=5,12$

Secara detail hasil perhitungan nilai DP), DPMO dan Sigma yang diperoleh dari bulan Oktober 2015 sampai dengan September 2016 dapat dilihat pada tabel 2 di bawah ini:

Tabel 2. Perhitungan Nilai DPO, DPMO, dan Nilai Sigma

\begin{tabular}{|c|c|c|c|c|c|c|}
\hline Bulan & $\begin{array}{c}\text { Jumlah } \\
\text { Produksi }\end{array}$ & $\begin{array}{c}\text { Jumlah } \\
\text { Cacat }\end{array}$ & CTQ & DPO & DPMO & $\begin{array}{c}\text { Level } \\
\text { Sigma }\end{array}$ \\
\hline Oktober '15 & 797079 & 351 & 3 & 0,000146786 & 146,786 & 5,12 \\
\hline November '15 & 693618 & 487 & 3 & 0,000234039 & 234,0385 & 4,99 \\
\hline Desember '15 & 582047 & 503 & 3 & 0,000288064 & 288,0638 & 4,94 \\
\hline Januari '16 & 240124 & 179 & 3 & 0,000248483 & 248,4827 & 4,98 \\
\hline Februari '16 & 669426 & 289 & 3 & 0,000143904 & 143,9044 & 5,12 \\
\hline Maret '16 & 715685 & 233 & 3 & 0,000108521 & 108,5207 & 5,19 \\
\hline April '16 & 740359 & 215 & 3 & $9,67999 \mathrm{E}-05$ & 96,79989 & 5,22 \\
\hline Mei '16 & 611470 & 354 & 3 & 0,000192978 & 192,9776 & 5,05 \\
\hline Juni '16 & 754509 & 254 & 3 & 0,000112214 & 112,2143 & 5,18 \\
\hline Juli '16 & 808174 & 337 & 3 & 0,000138996 & 138,9965 & 5,13 \\
\hline Agustus '16 & 862640 & 281 & 3 & 0,000108581 & 108,5814 & 5,19 \\
\hline September '16 & 873872 & 341 & 3 & 0,000130072 & 130,0724 & 5,15 \\
\hline RATA - RATA & 695750,25 & 318,6666667 & 3 & 0,000162453 & 162,4532 & 5,105 \\
\hline
\end{tabular}

Pada tabel 2 dapat dilihat rata-rata nilai sigma perusahaan sekitar 5,1 . Secara penilaian sigma dapat diartikan bahwa proses pengendalian kualitas yang telah dilakukan sudah berjalan dengan baik. Pengendalian kualitas masih tetap diperlukan untuk meningkatkan nilai sigma yang diperoleh dalam rangka meminimalkan kemungkinan cacat terulang kembali.

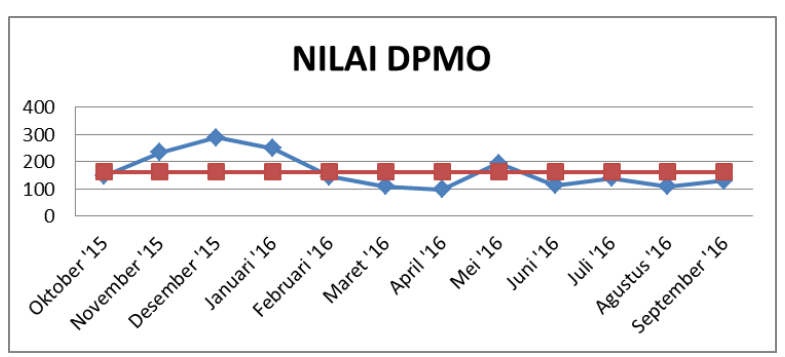

Gambar 1. Grafik Perkembangan Nilai DPMO

Grafik perkembangan DPMO di atas menunjukkan perubahan nilai dari tiap bulannya.
Pada bulan Oktober 2015 sampai dengan bulan Desember 2015 mengalami kenaikan, selanjutnya pada bulan Januari 2016 sampai dengan bulan April 2016 mengalami penurunan, selanjutnya kembali meningkat pada bulan Mei 2016, namun mengalami penurunan kembali pada bulan Juni 2016 sampai dengan September 2016. Nilai DPMO berpengaruh terhadap perubahan nilai sigma, semakin rendah nilai DPMO maka semakin tinggi nilai sigma yang dihasilkan.

\section{Analyze}

Analyze digunakan untuk mengetahui faktor-faktor yang menyebabkan terjadinya cacat produksi gula. Berdasarkan data yang didapat dengan wawancara dan pengamatan langsung pada proses produksi khususnya bagian bagging didapatkan beberapa faktor yang menyebabkan terjadinya produk reject.

1. Faktor manusia

Faktor yang mempengaruhi terjadinya cacat gula dari segi manusia diakibatkan oleh skill dan pengetahuan operator. Kurangnya 
ketelitian operator dalam melakukan pekerjaan dan pengalaman yang berbedabeda dari setiap operator menjadi salah satu penyebab terjadinya cacat.

2. Faktor Mesin

Dari sisi mesin, beberapa faktor yang terjadi adalah kecepatan pemakaian pada mesin conveyor dan mesin jet yang meyebabkan terjadinya sarung sobek dan lepasnya jahitan. Kondisi mesin dan kebersihan mesin yang kurang sehingga mesin mengalami kerusakan yang menganggu proses produksi. Ketidakakuratan mesin timbang yang meyebabkan hasil timbangan gula ada yang tidak sesuai dengan standar yang telah ditetapkan.

3. Faktor Metode

Penyebab terjadinya kecacatan dari sisi metode adalah perawatan mesin yang kurang efektif yang mengganggu jadwal produksi. Selama ini belum ada sistem perawatan mesin yang terschedule dengan baik sehingga performance mesin tidak bisa dimonitoring secara berkala.

\section{Improve}

Improve adalah rencana perbaikan produksi gula berdasarkan penyebab masalah yang didapatkan dari hasil analyze. Dalam tahapan ini disusun suatu usulan perbaikan atau rekomendasi untuk menekan kecacatan yang terjadi.

Perbaikan dari faktor manusia adalah perbaikan terhadap sistem pelatihan yang berkala terhadap operator untuk meningkatkan skill operator dalam menghadapi permasalahan proses dan menambah pengetahuan dalam menghadapi masalah-masalah baru. Program kesadaran untuk operator secara teratur harus dilakukan untuk pengembangan proses pengetahuan, keterampilan dan motivasi. Pengawasan yang dilakukan dapat berupa melihat produk yang dihasilkan.

Dari sisi mesin adalah dengan mengatur serta mengontrol keakuratan dan kecepatan mesin serta memeriksa kondisi dan kebersihan mesin disetiap pergantian shift, serta memantau kalibrasi dan pemeliharaan mesin. Hal ini dilakukan untuk menjaga agar mesin dapat menunjang produksi dengan baik. Kalibrasi dilakukan untuk menjaga kecepatan mesin sesuai dengan standar yang ada sehingga kecepatan conveyor dan mesin jet sesuai dengan standar. Kalibrasi timbangan perlu dilakukan secara berkala untuk menjaga keakuratan timbangan selama proses penimbangan.

Perbaikan dari sisi metode adalah dengan mengatur kembali jadwal perawatan mesin dan peralatan produksi sebaik mungkin agar proses produksi dapat berjalan dengan baik dan mengasilkan produk yang baik pula. Perlu dibuatkan pemeliharaan mesin secara berkala untuk memonitoring kondisi mesin.

\section{KESIMPULAN}

Berdasarkan pada penelitian yang telah dilakukan dapat diketahui periode Oktober 2015 - September 2016 mempunyai nilai rata - rata DPMO sebesar 162,4532 unit dengan nilai rata rata sigma sebesar 5,1 . kapabilitas perusahaan sudah terbilang baik namun harus dipertahankan dengan sebaik mungkin dan juga sebisa mungkin meningkatkan lagi upaya meminimalisir produk reject yang berdampak pada kerugian yang dialami perusahaan, serta nantinya akan dapat mencapai tingkat sigma industri kelas dunia.

Penyebab terjadinya cacat pada produksi gula adalah kurangnya ketelitian operator dalam melakukan pekerjaan dan pengalaman yang berbeda-beda. Selain itu, adanya ketidakstabilan kecepatan conveyor dan mesin jet, kondisi kebersihan mesin, kekurangakuratan mesin timbang, metode perawatan, dan pengontrolan yang belum efektif.

\section{DAFTAR PUSTAKA}

Defrianto, E. D., \& Farida. (2016). Analisis Kualitas Produk Gelas Kaca Crown dengan Metode Six Sigma dan Kaizen di PT. Semesta Raya Abadi Jaya Gresik. Jurnal Tekmapro, 10(1), 16-25.

Fransiscus, H., Juwono, C. P., \& Astari, I. S. (2014). Implementasi Metode Six Sigma DMAIC untuk Mengurangi Paint Bucket Cacat di PT X. Jurnal Rekayasa Sistem Industri, 3(2), 59-64.

Karenza, G. M., Adianto, H., \& Liansari, G. P. (2016). Pengurangan Jumlah Produk Cacat Kue Kering Nastar Keju di PT.Bonli Cipta Sejahtera Menggunakan Metode Six Sigma. Reka Integra, 4(2), 14-23.

Salomon, L. L., Ahmad, A., \& Limanjaya, N. D. (2017). Strategi Peningkatan mutu Part Bening Menggunakan Pendekatan Metode Six Sigma (Studi Kasus Departemen Injection di PT. KG). Jurnal IImiah Teknik Industri, 3(3), 156-165.

Salomon, L. L., Kosasih, W., \& Jap, L. (2017). Peningkatan Kualitas Benang DTY SIngle 150D/48F pada Mesin Cone Wender Menggunakan Metode Six Sigma dan 
Factorial Design di PT. Gemilang Indonesia. Jurnal Ilmiah Teknik Industri, 2(2), 1-11.

Wardhana, W., Harsono, A., \& Liansari, G. P. (2015). Implementasi Perbaikan Kualitas Menggunakan Metode Six Sigma Untuk Mengurangi Cacat Produk Sajadah Pada Perusahaan Pada PT. Pondok Tekstil Kreasindo. Reka Integra, 3(1), 85-96.

Wibowo, C. M. A., \& Aritonang, K. (2014). Penerapan Lean Six Sigma dan ActivityBased Costing Pada Perusahaan Garmen PT X. Jurnal Rekayasa Sistem Industri, $3(1), 10-19$.

Wisnubroto, P., \& Rukmana, A. (2015). Pengendalian Kualitas Produk dengan Pendekatan Six Sigma dan Analisis Kaizen Serta New Seven Tools sebagai Usaha Pengurangan Kecacatan Produk. Jurnal Teknik Industri, 8(1), 65-74.

Yanuarsih, B., Widaningrum, S., \& lqbal, M. (2012). Minimasi Waste Defect di PT. Eksonindo Multi Product Industri dengan Pendekatan Lean Six Sigma. Jurnal Rekayasa Sistem \& Industri, 1(2), 34-40. 